wird, schon wegen der Prognosen, die sie voraussetzt und die kein qualifizierter Gutachter wird verantworten wollen. Sollte es trotzdem geschehen, so steht praktisch außer Frage, dass dies zu einer Verurteilung der Schweiz durch den EGMR führen müsste - und damit zu einem unlösbaren Konflikt mit ihrer Verfassung.

Die Quintessenz: Emotional so stark befrachtete Fragen wie diese eignen sich nicht für Plebiszite. Das weiß man in der Schweiz eigentlich. Die Bundesverfassung von 1874 hatte die Todesstrafe in Friedenszeiten schon einmal abgeschafft. Dann aber ereignete sich in wenigen Jahren eine Serie schwerer Mordfälle, so dass der entsprechende Artikel durch eine der ersten Initiativen, die nach dem Inkrafttreten der neuen Verfassung ergriffen wurden, bereits 1879 wieder aufgehoben wurde. Erst 1942 sollte die Todesstrafe mit der Einführung des schweizerischen Strafgesetzbuchs, dessen Annahme daran fast gescheitert wäre, endgültig der Vergangenheit angehören (wenn zunächst auch nur in Friedenszeiten). Das hat erregte Diskussionen über ihre Wiedereinführung, vor allem Anfang der 70erJahre des vergangenen Jahrhunderts bei dem damals besonders aktuellen Delikts des Flugzeug-Attentats, nicht ausgeschlossen. Die Bundesrepublik verfügt über ähnliche Erfahrungen, unter anderem nach Morden an Taxifahrern. Heute ist der lebenslange Freiheitsentzug in der öffentlichen Diskussion an die Stelle der Kapitalstrafe getreten. Man erinnert sich entsprechender
Parolen des letzten Bundeskanzlers. In der Schweiz kam 2004 bei der Abstimmung über die Initiative der eingangs erwähnte Stimmungsumschwung in der öffentlichen Meinung hinzu. Er hinderte die Parteien offenkundig, im Vorfeld des Urnengangs gegen eine Maßregel, die sie im Parlament noch verworfen hatten, energischer Front zu machen. Für deren Einführung äußerte sich allein, wie schon im Nationalrat, die rechtskonservative SVP, die zu jener Zeit auch noch den zuständigen Bundesrat, d.h. den Justizminister stellte. Öffentlicher Widerspruch, wie ihn die Strafrechtslehrer der Schweiz in einer Boulevardzeitung erhoben, musste unter diesen Umständen wirkungslos bleiben.

Wenn man aus alledem eine Lehre ziehen kann, dann ist es die, dass die Wissenschaft im Zeitalter populistischer Gesetzgebung nicht früh und nicht entschieden genug Einspruch erheben kann, wenn sich legislatorische Sündenfälle ankündigen, wie etwa bei der nachträglichen Sicherungsverwahrung und jetzt mit der unseligen Diskussion über eine Verschärfung des Jugendstrafrechts - um sich, auch im Falle des Scheiterns, wenigstens nicht sagen zu müssen, dass sie zur falschen Zeit geschwiegen hat.

Der Verfasser lehrte Strafrecht an der Universität Basel. Er repräsentiert eine Generation liberaler Strafrechtsprofessoren, die unsere Rechtskultur prägen.

\title{
Sicherungsverwahrung nach deutschem StGB
}

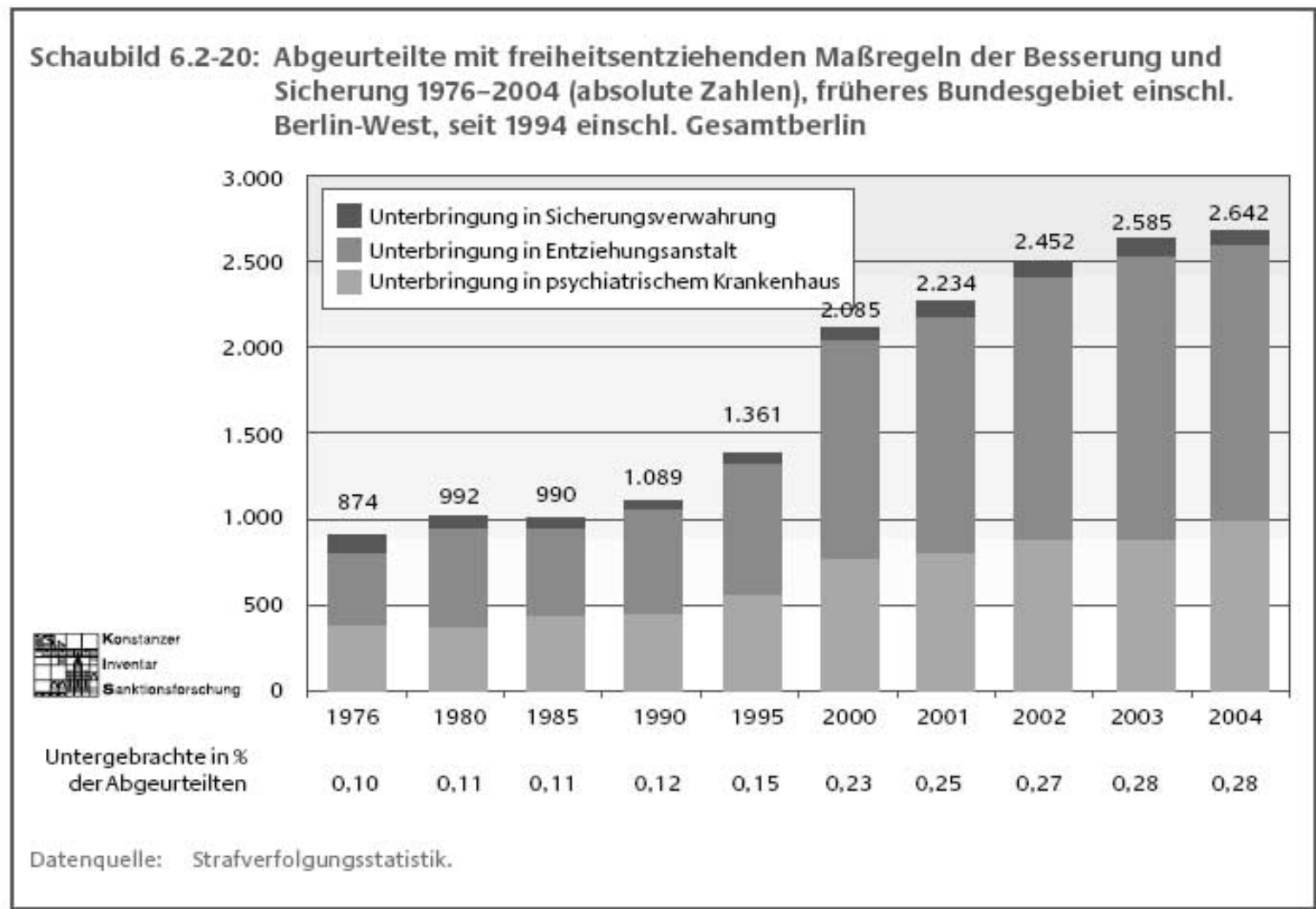

Nach dieser dem deutschen Sicherheitsbericht entnommenen Tabelle steigen die Maßregeln, aber die 1998 erweiterte Unterbringung in der Sicherungsverwahrung bleibt konstant. Nicht umgesetzt wurde $\$ 66$ a StGB (vorbehaltene Sicherungsverwahrung) und auch bei der viel diskutierten nachträglichen Sicherungsverwahrung gibt es so gut wie keine rechtskräftigen Entscheidungen. Ullenbruch kommentiert die sechs Reformgesetze 1998-2007, das siebte Gesetz zur Sicherungsverwahrung von Jugendlichen ist noch nicht umgesetzt, in NStZ 2007, S. $62 \mathrm{ff}$ und NStZ 2008, S. 5 ff. Die höchstrichterlichen Anforderungen sind hoch. Die Vollstreckungsgerichte judizieren sehr restriktiv. 